\title{
MARKO SNOJ
}

\section{COBISS: 1.03}

Prispevek prinaša zgodovinski in etimološki prikaz samo v slovenščini znane besede $n e-$ bina »cvetica astra«, ki je pri nas zapisana šele v 19. stoletju, a je njen obstoj posredno dokazljiv že za 18. stoletje. Čeprav je cvet nebine vijoličasto modre in ne nebesno modre barve, slovensko poimenovanje te cvetice po nebesni modrini ni osamljeno, saj podobno pomensko motivacijo najdemo tudi v nekaterih drugih jezikih.

Ključne besede: slovenščina, etimologija, rastlinska imena, pomenska motivacija

\section{The lexeme nebina}

This article offers a historical and etymological overview of the lexeme nebina 'aster (flower)', which is attested only in Slovenian. This word was only recorded in the nineteenth century, but its existence is already indirectly attested in the eighteenth century. Even though the flower of the aster is violet-blue and not sky blue, the Slovenian designation for this flower based on sky blue is not isolated because a similar semantic motivation can also be found in some other languages.

Keywords: Slovenian, etymology, plant names, semantic motivation

1 Beseda, ki je, kot kaže, samo slovenska, se je pri nas slovarsko prvič pojavila pri Pleteršniku (1894: 683), in sicer kot izpis iz Tuškove druge izdaje prirodopisa rastlinstva A. Pokornega iz leta 1872. Pleteršnik, ki jo je onaglasil nệbina, jo po Tušku navaja le v terminološki zvezi kitajska nebina »die Chinesische Sternblume, Aster Chinensis«. A že pred tem jo v pomenu »Aster amellus« navaja hrvaški leksikograf Bogoslav Šulek, ki kot vir navaja Freyerjevo zbirko rastlinskih imen iz Kranjske, in sicer tisti del, ki črpa iz gradiva Franca Antona Breckerfelda (1740-1806).1 V 20. stoletju je nebína, kot je beseda onaglašena ${ }^{2}$ v Slovarju slovenskega knjižnega jezika, postala sinonim za astro katere koli vrste (SSKJ II: 12). Posamezne vrste tega rodu strokovni jezik razlikuje s prilastki, npr. gorska nebina »Aster amellus«, alpska nebina »Aster alpinus«, obmorska nebina »Aster tripolium«. Taksonomsko ime za Tuškovo in Pleteršnikovo kitajsko nebino je danes Callistephus chinensis. Sodobna besedna

$1 \quad$ Šlek 1879: 257 (ki na začetnih straneh napačno piše J. A. Brekerfeld); Praprotnik 2007: 47. Leta 1836 natisnjena Freyerjeva zbirka je goli seznam slovenskih rastlinskih poimenovanj brez latinskih znanstvenih imen.

2 Pri tvorjenkah s pripono -ina iz neakutiranih samostalniških osnov pričakujemo naglas na priponi, prim. pri Pleteršniku 1894-95 perína iz perộ in zlatína iz zlatộ. 
družina poleg iz te besede sestoji le še iz poimenovanja družine nebínovke $»$ Asteraceae $\ll .3$

1.1 Potrditev, da je slovenska beseda nebina obstajala vsaj že v 18. stoletju, najdemo v Pohlinovem trijezičnem slovarju iz leta 1781 v zapisih Nebinaft »himmelblau, aereus, cæruleus« in Nebine, ki mu avtor pripiše isti pomen (Pohlin 1781: s. v., neoštevilčena str. 154). Nemški prevedek pomeni »nebesno moder«, prvi latinski »bronaste barve« in drugi »temno moder«. Prvi zapis ima dve možni branji, nebínast in nebinjast, 4 drugega je treba brati nebinji. 5 Iz obeh pridevnikov sklepamo o motivirajoči besedi nebina, iz katere je prvi tvorjen s pripono -(j)ast $<*_{-}\left({ }^{\prime}\right)$ astb za izražanje podobnosti, drugi pa iz *-ji<*-’bjb za izražanje svojine in širše povezanosti, ki vključuje tudi podobnost. 6 Besedotvorno razmerje med motiviranima pridevnikoma nebinast in nebinji ter $\mathrm{v} 18$. stoletju posredno potrjeno motivirajočo besedo nebina je primerljivo z besedotvornim razmerjem med pridevnikoma bábast in bâbji ter motivirajočo besedo bába. Barvni pridevnik, izpeljan s pripono -(j)ast iz rastlinskega imena, ima vzporednico v pridevniku vijộličast iz vijộlica.

2 Obravnavana beseda je tvorjenka iz samostalnika nebộ, kakor je npr. rastlinsko ime jastrebína »Galega« tvorjeno iz jâstreb ali črnobína »Scrophularia« iz črnóba. Možnosti, da bi bila nebina izvorno kaj drugega, skorajda ni. Fonetično bi sicer lahko nastala po betacizmu iz *nevina, kar je v pomenu »nedolžnost« potrjeno v zahodnoslovanskih jezikih in stari ruščini (ÈSSJa 1999: 79), a smiselne pomenske zveze med pojmoma »nedolžnost « in »rastlina Aster « ni mogoče najti, ${ }^{7}$ zato taka domneva ne bi imela nobene vrednosti.

2.1 Najpogostejša pomenska motivacija za poimenovanje nebine je »zvezda«, saj oblika cveta te rastline dejansko spominja na zvezdo. Tako so pomensko motivirana poimenovanja gr. $\dot{\alpha} \tau \eta \dot{\eta} \rho$ (od tod prevzeto lat. aster), narečno nem. Sternkraut, Sternblume (Marzell 1943: 497), star. sloven. tudi zvệzdnik, zvệzdnica (Pleteršnik 1895: 946), star. hrv. zvezdenka, zvezdenica, zvezdača trava (po Vitezoviću navaja Vajs 2003: 355) ipd. A kljub dejstvu, da so v naših krajih domače nebine bolj vijoličasto modre kot nebesno modre, je nebina neredko poimenovana prav

3 Termin nebinovka, ki ga SSKJ ne navaja, ima BTS na 28 mestih in FTS na treh, v jezikovnem korpusu Gigafida se pojavi 119-krat.

4 Pohlin pogosto ne zapisuje fonema $j$ neposredno za $n$, prim. Dina »Melone, Melopepo«, Gonâzh »Treiber bey der Jagd, Compulsor venatorius«.

$5 \quad$ Kakor pri Pohlinu npr. Uzhirejshne za včerajšnji. Nekako tako bere že Gutsman 1789: 526, ki v slovensko-nemškem delu piše Nebinaft, nebini »himmelblau«.

6 eSSKJ v sestavku opičji navaja pomen »ki je v zvezi z opicami« in tretji podpomen »ki je podoben, soroden $\mathrm{z}$ opicami

7 Za nebino namreč v dostopnih virih ni izpričano, da bi jo kot nekatere druge rastline, npr. navadno plahtico, »Alchemilla vulgaris«, uporabljali pri pripravi kopeli, ki naj bi dekletom povrnila nedolžnost (o tem gl. Snoj pri Bezlaju 2005: 353). 
po modri barvi. Šulek (1879: 244) navaja izraz modrinščak»Aster amellus« iz Križevcev v hrvaškem Prigorju, že Bauhinus (1623: 267) pa isto cvetico imenuje Aster cæruleus Italicus. Ta izraz vsebuje lat. pridevnik caeruleus »temno moder, nebesno moder«, ki je po disimilaciji nastal iz *caeluleus, tvorjenke prek manjšalnice caelulum iz caelum »nebo« (Walde - Hofmann 1982: 133).8 Motivacijo po nebu najdemo tudi v narečno nem. poimenovanju Himmelsgebüsch $\gg$ Aster amellus«.9

2.2 Zakaj je vijoličasto modra cvetica poimenovana po nebesni modrini, ni popolnoma jasno. Morda je bilo dojemanje barvnih odtenkov pred dvesto in več leti nekoliko drugačno, manj natančno od današnjega, a se zdi mogoče tudi, da nebina ni poimenovana po modri barvi jasnega neba sredi dneva, temveč po oni ob sončnem vzhodu ali zahodu, ko je ob povečani atmosferski vlagi nebo vijoličasto modro, to barvo pa neredko pojmujejo kot neposredni odsev nebes.10

\section{LITERATURA}

Bauhinus 1623 = Casparus Bauhinus, Pinax Theatri botanici, Basileae Helvet., 1623.

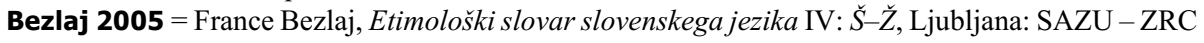
SAZU (izd.) - Založba ZRC (zal.), 2005.

BTS = Franc Batič - Borislava Košmrlj - Levačič (ur.), Botanični terminološki slovar 〈https://isjfr. zrc-sazu.si/sl/terminologisce/slovarji/botanicni\#v, 8. 8. 2017〉.

ÈSSJa 1999 = Ėtimologičeskij slovar' slavjanskih jazykov: praslavjanskij leksičeskij fond 25, Moskva: Nauka, 1999.

eSSKJ = Slovar slovenskega knjižnega jezika 2016 〈www.fran.si, 8. 8. 2017〉.

FTS = Marjeta Humar idr. (ur.), Farmacevtski terminološki slovar $\langle$ https://isjfr.zrc-sazu.si/sl/terminologisce/slovarji/farmacevtski\#v, 8. 8. 2017).

Gutsman 1789 = Oswald Gutsmann, Deutsch-windisches Wörterbuch mit einer Sammlung der verdeutschten windischen Stammwörter und einiger vorzüglichern abstammenden Wörter, Klagenfurt: im Verlage bey Ignaz Aloys edlen von Kleinmayer, 1789.

Marzell 1943 = Heinrich Marzell, Wörterbuch der deutschen Pflanzennamen 1, Leipzig: Verlag von S. Hirzel, 1943.

Pohlin $1781=$ R. P. Marcus a S. Antonio Paduano Augustinianus Discalceatus inter Academicos Operosos Labacenses dictus: Novus, TU MALU BESEDISHE TREH JESIKOV, Laibach: Johann Friedrich Eger, 1781.

Pleteršnik 1894-95 = Maks Pleteršnik, Slovensko-nemški slovar, Ljubljana: Knezoškofijstvo, 1894-1895 〈www.fran.si, 8. 8. 2017〉.

Praprotnik 2007 = Nada Praprotnik, Henrik Freyer in njegov seznam slovenskih rastlinskih imen (Verzeichniß flavischen Pflanzen-Namen) iz leta 1836, v: Scopolia: revija Prirodoslovnega muzeja Slovenije 61, Ljubljana: Prirodoslovni muzej Slovenije, 2007, 1-99.

SSKJ = Slovar slovenskega knjižnega jezika $\mathrm{I}-\mathrm{V}$, Ljubljana: SAZU oz. ZRC SAZU (izd.) - DZS (zal.), 1970-1991 〈www.fran.si, 8. 8. 2017〉.

$8 \quad$ Latinsko caeruleus je tudi eden Pohlinovih prevedkov pridevnikov nebin(j)ast in nebinji.

9 Navaja Marzell 1943: 498, ki domneva po nebu motivirano poimenovanje zato, ker nebine rastejo v skupinah, ki naj bi spominjale na zvezdnato nebo.

10 Po vsej Sloveniji se konec novembra in v začetku decembra otrokom razlaga večerna zarja kot pečica, v kateri Miklavž peče piškote. Peče jih seveda v nebesih. 
Šulek 1879 = Bogoslav Šulek, Jugoslavenski imenik bilja, Zagreb: troškom Jugoslavenske akademije znanostih i umjetnostih, 1879.

Vajs 2003 = Nada Vajs, Hrvatska povijesna fitonimija, Zagreb: Institut za hrvatski jezik i jezikoslovlje, 2003.

Walde - Hofmann 1982 = Alois Walde - Johann Baptist Hofmann, Lateinisches etymologisches Wörterbuch, Heidelberg: Carl Winter Universitätsverlag, 51982.

\section{SUMMARY}

\section{The lexeme nebina}

The lexeme nebina 'aster' (Aster spp., especially A. amellus) was first recorded in a Slovenian text in 1872 , but is already indirectly attested in the eighteenth century. This article focuses on its etymological explanation. It determines that it is derived from the noun nebo 'sky, heaven'. It continues with a possible explanation of the fact that not only Slovenian names this violet-blue flower after the sky, which is usually ascribed a lighter and purer shade of blue. One possible explanation of this fact is the hypothesis of imprecision in understanding shades of color two hundred and more years ago, and another is that the flower is not named after the light color of a clear sky at midday, but after the color close to sunrise or sunset, when increased moisture in the atmosphere gives the sky a violet-blue color, and this color is often understood as a direct reflection of the heaven. 